\title{
Monitoring Microcirculatory Blood Flow with a New Sublingual Tonometer in a Porcine Model of Hemorrhagic Shock
}

\author{
Péter Palágyi, ${ }^{1}$ József Kaszaki, ${ }^{2}$ Andrea Rostás, ${ }^{2}$ Dániel Érces, ${ }^{2}$ \\ Márton Németh, ${ }^{1}$ Mihály Boros, ${ }^{2}$ and Zsolt Molnár ${ }^{1}$ \\ ${ }^{1}$ Department of Anesthesiology and Intensive Therapy, University of Szeged, 6 Semmelweis Street, Szeged 6725, Hungary \\ ${ }^{2}$ Institute of Surgical Research, University of Szeged, 6 Szökefalvi-Nagy Béla Street, Szeged 6720, Hungary \\ Correspondence should be addressed to Zsolt Molnár; zsoltmolna@gmail.com
}

Received 21 January 2015; Revised 23 March 2015; Accepted 24 March 2015

Academic Editor: Stephen M. Cohn

Copyright (C) 2015 Péter Palágyi et al. This is an open access article distributed under the Creative Commons Attribution License, which permits unrestricted use, distribution, and reproduction in any medium, provided the original work is properly cited.

Tissue capnometry may be suitable for the indirect evaluation of regional hypoperfusion. We tested the performance of a new sublingual capillary tonometer in experimental hemorrhage. Thirty-six anesthetized, ventilated mini pigs were divided into shamoperated $(n=9)$ and shock groups $(n=27)$. Hemorrhagic shock was induced by reducing mean arterial pressure (MAP) to $40 \mathrm{mmHg}$ for $60 \mathrm{~min}$, after which fluid resuscitation started aiming to increase MAP to $75 \%$ of the baseline value (60-180 min). Sublingual carbon-dioxide partial pressure was measured by tonometry, using a specially coiled silicone rubber tube. Mucosal red blood cell velocity (RBCV) and capillary perfusion rate (CPR) were assessed by orthogonal polarization spectral (OPS) imaging. In the 60 min shock phase a significant drop in cardiac index was accompanied by reduction in sublingual RBCV and CPR and significant increase in the sublingual mucosal-to-arterial $\mathrm{PCO}_{2}$ gap $\left(\mathrm{P}_{\mathrm{SL}} \mathrm{CO}_{2}\right.$ gap), which significantly improved during the 120 min resuscitation phase. There was significant correlation between $\mathrm{P}_{\mathrm{SL}} \mathrm{CO}_{2}$ gap and sublingual $\mathrm{RBCV}(r=-0.65, p<0.0001)$, CPR $(r=-0.64, p<0.0001)$, central venous oxygen saturation $(r=-0.50, p<0.0001)$, and central venous-to-arterial $\mathrm{PCO}_{2}$ difference $(r=0.62, p<0.0001)$. This new sublingual tonometer may be an appropriate tool for the indirect evaluation of circulatory changes in shock.

\section{Introduction}

Disturbances of the microcirculation are tightly linked to circulatory failure of different origin; thus evaluation of the microcirculatory status has gained increasing importance in the diagnosis and treatment of critically ill patients. It is recognized that in spite of the normal values of global oxygen delivery regional tissue hypoperfusion may exist, which cannot be detected by conventional monitoring tools $[1,2]$. Besides, compensatory mechanisms may lead to the normalization of macrohemodynamic parameters in the early phase of circulatory shock, and silently ongoing microcirculatory insufficiencies can cause cellular hypoxia and metabolic dysfunctions, eventually leading to organ failure [3].

The measurement of the partial pressure of carbon dioxide $\left(\mathrm{PCO}_{2}\right)$ in tissues is a potentially feasible technique for the indirect evaluation of the microcirculation $[4,5]$. This parameter reflects the adequacy of regional microvascular blood flow, as intramucosal $\mathrm{PCO}_{2}$ is inversely related to the proportion of well perfused capillaries, and is mainly dependent on tissue perfusion [6, 7]. However, acute increases or decreases in the $\mathrm{PCO}_{2}$ of the arterial blood $\left(\mathrm{P}_{\mathrm{a}} \mathrm{CO}_{2}\right)$ result in comparable changes in the tissue $\mathrm{PCO}_{2}$ [8]; thus it should be interpreted in relation to $\mathrm{P}_{\mathrm{a}} \mathrm{CO}_{2}$. By subtracting $\mathrm{P}_{\mathrm{a}} \mathrm{CO}_{2}$ from the tissue $\mathrm{PCO}_{2}$, special gap values can be calculated which are more accurate than the mucosal $\mathrm{PCO}_{2}$ alone, as they are independent of concurrent changes in $\mathrm{P}_{\mathrm{a}} \mathrm{CO}_{2}$. Although there is no consensus on the most sensitive hemodynamic and laboratory parameters indicating the onset of shock, the tissue-to-arterial $\mathrm{PCO}_{2}$ gap may provide an early and important additional signal of perfusion failure $[1,2,9]$. In addition, the tissue-to-arterial $\mathrm{PCO}_{2}$ gap values also have prognostic importance $[1,10,11]$; therefore the monitoring of tissue levels of $\mathrm{CO}_{2}$ may be helpful in titrating therapeutic interventions in critical states [12], or in selecting 
patients with compromised physiologic reserve who require expanded hemodynamic monitoring.

Different sites of the gastrointestinal tract are available for the purpose of tissue capnometry and the assessment of the adequacy of mucosal blood flow. As $\mathrm{PCO}_{2}$ results gained from the stomach and the sublingual regions proved to be interchangeable $[6,13]$, and the latter is free of some limitations of gastric tonometry, such as interference of gastric acid, enteral feeding, and potential pitfalls of $\mathrm{pHi}$ calculation [14], sublingual tonometry may be a useful alternative for measuring mucosal $\mathrm{PCO}_{2}$. Though promising, this technique is still not available at the bedside because of the lack of a suitable monitoring device; hence clinical and experimental evidence on its efficacy is also missing.

It is generally acknowledged that monitoring of the sublingual microcirculation, the only site of intravital microscopy (IVM) available at the point of care for most critically ill patients, is of particular prognostic value [3]. In our institute a special instrument has been designed and manufactured for the measurement of sublingual $\mathrm{PCO}_{2}$ (Figure 1), which is a further development of a gastric tonometer $[15,16]$. The performance of this new probe was recently tested in vitro and also in patients with respiratory disease, and the results showed its suitability for sublingual tonometry [17].

The main goal of the current study was to test this new sublingual probe in a porcine model of hemorrhagic shock and compare its performance to direct microcirculatory measurements with IVM using the orthogonal polarization spectral (OPS) imaging technique. Another aim was to investigate how the capnometry-derived values relate to global indicators of hemodynamic changes during hemorrhage and resuscitation. We also hypothesized that if the same diagnostic end points can be reached, sublingual capnometry could offer a technically simpler, alternative method to monitor sublingual microcirculatory changes noninvasively.

\section{Materials and Methods}

The experiments were carried out in strict adherence to the National Institute of Health guidelines for the use of experimental animals and the study was approved by the Ethics Committee and the Institutional Animal Care and Use Committee at the University of Szeged. The study was conducted in the research laboratory of the Institute of Surgical Research in a manner that does not inflict unnecessary pain or discomfort upon the animals.

2.1. Animals and Instrumentation. Thirty-six Vietnamese mini pigs of both genders, weighing $16-25 \mathrm{~kg}$, underwent a $24 \mathrm{hr}$ fasting preoperatively with free access to water; the animals were randomly allocated into control (shamoperated, $n=9$ ) and hemorrhagic shock groups (shock, $n=27$ ). Anesthesia was induced by an intramuscular injection with a mixture of ketamine $\left(20 \mathrm{mg} \mathrm{kg}^{-1}\right)$ and xylazine $\left(2 \mathrm{mg} \mathrm{kg}^{-1}\right)$ and maintained with a continuous infusion of propofol ( $50 \mu \mathrm{g} \mathrm{min}^{-1} \mathrm{~kg}^{-1} \mathrm{iv}, 3 \mathrm{mg} \mathrm{kg}^{-1} \mathrm{hr}^{-1}$ ). After endotracheal intubation, the animals were mechanically ventilated with room air (Harvard Apparatus, South Natick, MA, USA).

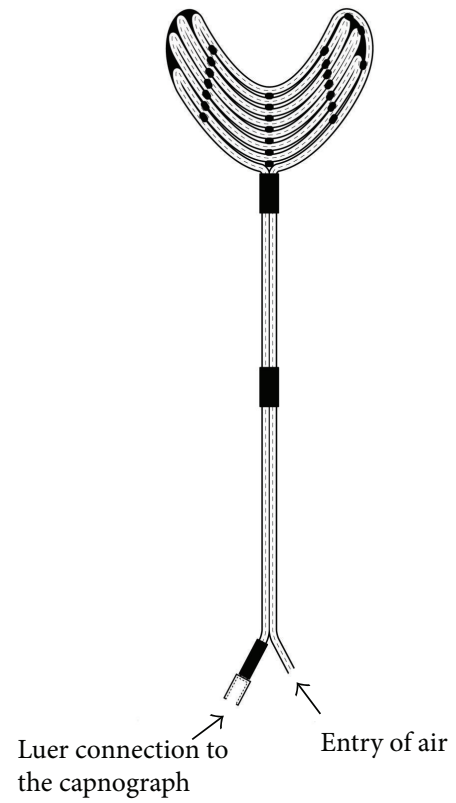

FIGURE 1: The new capillary tonometer. Illustration of the new sublingual tonometer applied during the examinations.

The tidal volume was set at $9 \pm 2 \mathrm{~mL} \mathrm{~kg}^{-1}$, and the respiratory rate was adjusted to maintain the end-tidal partial pressure of carbon dioxide $\left(\mathrm{EtCO}_{2}\right)$ and $\mathrm{P}_{\mathrm{a}} \mathrm{CO}_{2}$ in the range of 3545 Torr (4.7-6.0 Pa). The depth of anesthesia was assessed by monitoring the jaw tone regularly. The animals were placed in supine position on a heating pad for maintenance of the body temperature between 36 and $37^{\circ} \mathrm{C}$.

For measurement of the sublingual $\mathrm{PCO}_{2}\left(\mathrm{P}_{\mathrm{SL}} \mathrm{CO}_{2}\right)$ the new sublingual capillary tonometer (see below) was placed under the tongue, and a specially designed latex face mask was used to close the oral cavity. Capnography was performed with a Microcap handheld capnograph (Oridion Medical Ltd, Jerusalem, Israel). The sublingual mucosal-to-arterial $\mathrm{PCO}_{2}$ difference $\left(\mathrm{P}_{\mathrm{SL}} \mathrm{CO}_{2}\right.$ gap) was calculated by subtracting $\mathrm{P}_{\mathrm{SL}} \mathrm{CO}_{2}$ from the simultaneously taken $\mathrm{P}_{\mathrm{a}} \mathrm{CO}_{2}$ values.

For central venous access the left jugular vein was catheterized. A three-lumen central venous catheter $(7 \mathrm{~F}$, Edwards Lifesciences LLC, Irvine, USA) was introduced for blood sampling and fluid administration using aseptic surgical technique. The central venous pressure (CVP) was monitored continuously with a computerized dataacquisition system (SPELL Haemosys; Experimetria Ltd., Budapest, Hungary). For hemodynamic measurements a special thermodilution catheter (Pulsiocath, PULSION Medical Systems AG, Munich, Germany) was placed into the left femoral artery. The cardiac output was monitored by transpulmonary thermodilution and continuous pulse contour analysis (PiCCO method). The right carotid artery was also catheterised for bleeding (7 F, PE, Access Technologies, Illinois, USA). The blood gas measurements were carried out by taking arterial and central venous blood samples simultaneously according to the study protocol, which were then analyzed by cooximetry with a blood gas analyzer (Cobas b221, Roche, Austria). Simplified oxygen extraction 
rate $\left(\mathrm{O}_{2} \mathrm{ER}\right)$ was calculated according to the standard formula from arterial $\left(\mathrm{SaO}_{2}\right)$ and central venous oxygen saturations $\left(\mathrm{ScvO}_{2}\right): \mathrm{O}_{2} \mathrm{ER}=\left(\mathrm{SaO}_{2}-\mathrm{ScvO}_{2}\right) / \mathrm{SaO}_{2}$. From the central venous and arterial blood gas values the central venous-toarterial $\mathrm{PCO}_{2}$ gap $\left(\mathrm{PcvaCO}_{2}\right)$ was also determined.

For direct evaluation and noninvasive visualization of the sublingual microcirculation the intravital OPS imaging technique (Cytoscan A/R, Cytometrics, Philadelphia, PA, USA) was used. A $10 \mathrm{x}$ objective was placed onto the sublingual mucosa, and microscopic images were recorded with an S-VHS video recorder (Panasonic AG-TL 700, Matsushita Electric Ind. Co. Ltd, Osaka, Japan). Quantitative assessment of the microcirculatory parameters was performed offline by frame-to-frame analysis of the videotaped images. Red blood cell velocity (RBCV; $\mu \mathrm{m} \mathrm{s}^{-1}$ ) changes in the postcapillary venules were determined in three separate fields by means of a computer-assisted image analysis system (IVM Pictron, Budapest, Hungary) [18]. Capillary perfusion rate (CPR; 1/1) was determined as the length of continuously perfused microvessels per total length of capillaries in the observational area. During quantitative assessment of CPR we used a diameter limitation for determination of the microvascular network. Exclusively those vessels were selected for analysis, whose diameters were less than $20 \mu \mathrm{m}$. All microcirculatory evaluations were performed by the same investigator.

2.2. Description of the New Tonometric Probe. The new sublingual capillary tonometer (Mediszintech Ltd, Budapest, Hungary) is a specially coiled silicone rubber tube (ID: $1.5 \mathrm{~mm}$, OD: $2.0 \mathrm{~mm}$, and length: $640 \mathrm{~mm}$ ) with high permeability for gases, which is formed into a multiple $\mathrm{V}$-shape by using a mould and is glued along five lines (Figure 1). To prevent the soft-walled tube from flattening, a polyamide fiber of $0.3 \mathrm{~mm}$ thickness is inserted along its full length. Thereby after folding the tube a sufficient gap remains ensuring the free transport of the filling medium. The afferent and deferent parts of the tube are fixed together at their branching. The end of the deferent tube is equipped with a Luer connector. The filling material is room air, which equilibrates quickly with the $\mathrm{PCO}_{2}$ content of the capillaries in the sublingual mucosa. After the required equilibration time it can be aspirated and measured by capnometry. The duration of the full equilibration of the sublingual probe is about 15 minutes. The $\mathrm{PCO}_{2}$ of the aspirated gas is measured by infrared spectrophotometry. The results are immediately displayed in units of $\mathrm{mmHg}$.

2.3. Experimental Protocol. The preparation period was followed by a $30 \mathrm{~min}$ resting period. After baseline measurements at $0 \mathrm{~min}\left(T_{0}\right)$ in the shock group, hemorrhagic shock was induced by bleeding the animals through the right carotid arterial catheter into a heparin $\left(100 \mathrm{IU} \mathrm{mL}^{-1}\right)$ containing reservoir. The target mean arterial pressure (MAP) of approximately $40 \mathrm{mmHg}$ was reached in $10-15 \mathrm{~min}$ and was kept by repeated bleeding periods until the 60th min of the experiment $\left(T_{2}\right)$. The amount of shed blood was precisely monitored. The average blood loss was about $25 \mathrm{~mL} \mathrm{~kg}^{-1}$ 15 min after the onset of hemorrhage, which increased to an average of around $40 \mathrm{~mL} \mathrm{~kg}^{-1}$ by the end of bleeding at $T_{2}$. This was about $50 \%$ of the animals' circulating blood volume. At $60 \mathrm{~min}\left(T_{2}\right)$ volume resuscitation with colloid solution (hydroxyethyl starch $130 \mathrm{kDa} / 0.4,6 \%$ Voluven, Fresenius, Germany) was started. $75 \%$ of the starting MAP was reached in 10-15 min. In case of decreasing blood pressure further colloid infusion was given, but the total amount of colloid infusion was maximized in $25 \mathrm{~mL} \mathrm{~kg}^{-1}$. This means that the pigs were partially resuscitated and remained hypovolemic in the following period between 60 and $180 \mathrm{~min}\left(T_{2}\right.$ and $T_{6}$ ). The reason for choosing this protocol was to enable us to investigate the alterations of different macro- and microcirculatory parameters in two well separated periods: severe shock and moderate hypovolemia. Hemodynamic, arterial, and central venous blood gas measurements and tissue capnometry were repeated and recorded every $30 \mathrm{~min}$ for duration of $3 \mathrm{hr}\left(T_{0}-T_{6}\right)$. Intravital video microscopy was performed at baseline, at $60\left(T_{2}\right)$, and at $180 \mathrm{~min}\left(T_{6}\right)$ (Figure 2).

Animals in the control group were not submitted to bleeding. They underwent the same operation procedure and received the same instrumentation and monitoring. In this group $0.9 \%$ sodium chloride was infused at a rate of $10 \mathrm{~mL} \mathrm{~kg}^{-1} \mathrm{~h}^{-1}$ during the experiment. Hemodynamic, blood gas analysis and microcirculatory measurements were performed at the same time points.

2.4. Statistical Analysis. The statistical software package SigmaStat for Windows (Jandel Scientific, Erkrath, Germany) was applied for data analysis. After testing for normality parametric methods were used. Two-way repeated measures analysis of variance (ANOVA) was applied for statistical analysis. For the analysis of differences between the shamoperated and the hemorrhagic shock groups, the time dependent differences from the baseline $\left(T_{0}\right)$ for each group were assessed by Holm-Sidak post hoc test. When we examined the effect of partial resuscitation starting at 60 minutes $\left(T_{2}\right)$, we performed multiple pairwise comparisons of $T_{3}-T_{6}$ results versus $T_{2}$ data serving as control. The pairwise comparison of different variables was made with Pearson-correlation. $p$ values $<0.05$ were considered statistically significant. The numeric data in the text and values on the figures are given as mean and standard deviations.

\section{Results}

3.1. Hemorrhagic Shock Phase $\left(T_{0}\right.$ to $\left.T_{2}\right)$. Severe shock state was achieved in the animals of the shock group as indicated by marked and significant changes in macrohemodynamics during the first 60 minutes: MAP decreased, heart rate (HR) increased, and cardiac index (CI) and global end-diastolic volume index (GEDVI) decreased significantly (Figures 3(a), 3(b), 3(c), and 3(d)). This change in global hemodynamics was accompanied by a significant drop in base excess (BE) in the shock group $\left(T_{0}: 6.4 \pm 2.1\right.$ and $T_{2}: 1.1 \pm 2.8 \mathrm{mmol} \mathrm{L}^{-1} p<$ $0.05)$, while there was no similar change in the sham group $\left(T_{0}: 5.6 \pm 1.8\right.$ and $\left.T_{2}: 5.9 \pm 1.9 \mathrm{mmol} \mathrm{L}^{-1}\right)$. We detected significant increases both in the $\mathrm{P}_{\mathrm{SL}} \mathrm{CO}_{2}$ and in the $\mathrm{P}_{\mathrm{SL}} \mathrm{CO}_{2}$ gap 

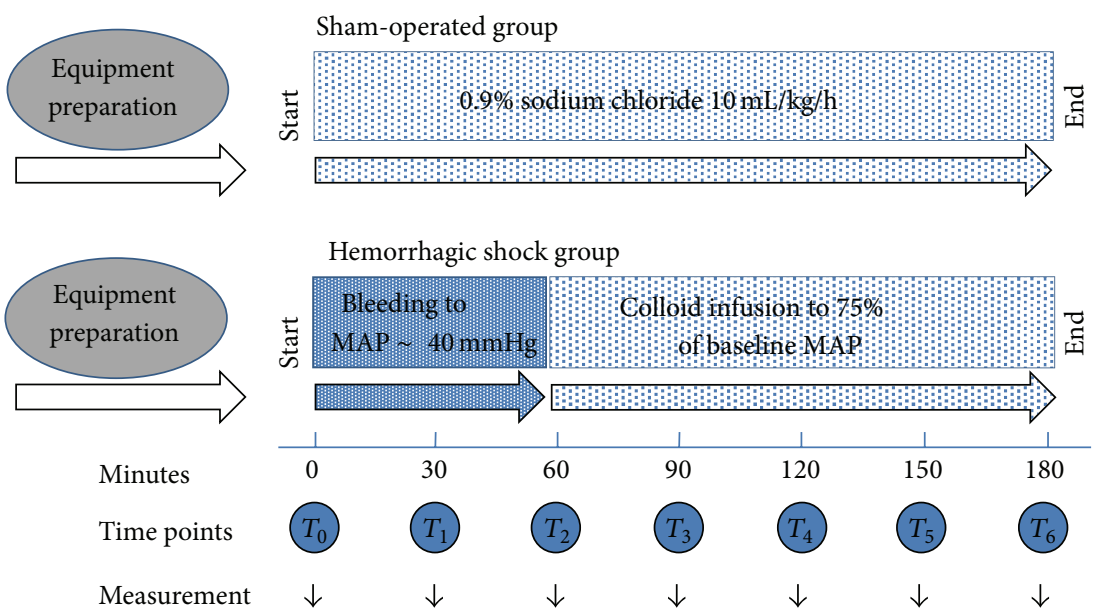

Blood gas analysis
Hemodynamics
Sublingual tonometry
Video microscopy

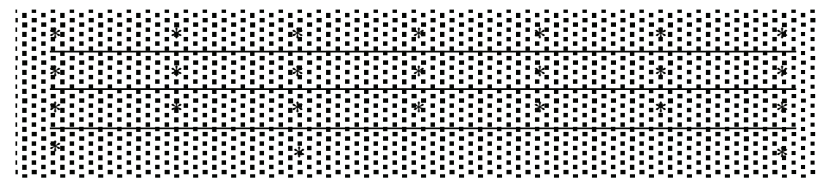

FIGURE 2: Experimental protocol. Flow diagram representing the experimental protocol in both groups of animals. MAP is mean arterial pressure, $T_{0}-T_{6}$ are seven time points of measurements, and $*$ indicates the implementation of different types of measurements.

values (Figures 4(a) and 4(b)). The sublingual postcapillary red blood cell velocity $\left(\mathrm{RBCV}_{\mathrm{SL}}\right)$ and the sublingual capillary perfusion rate $\left(\mathrm{CPR}_{\mathrm{SL}}\right)$ decreased significantly (Figures 5(a) and 5(b)). The central venous blood derived variables showed characteristic alterations too: corresponding to the significant increase of the oxygen extraction rate the $\mathrm{ScvO}_{2}$ decreased during bleeding, while the $\mathrm{PcvaCO}_{2}$ increased (Figures 6(a), $6(\mathrm{~b})$, and $6(\mathrm{c}))$. These changes at 60 minutes were significant compared to the baseline values and differed significantly from the corresponding values of the sham-operated animals.

3.2. Partial Resuscitation Phase $\left(T_{2}\right.$ to $\left.T_{6}\right)$. Statistically significant alterations were found regarding MAP, $\mathrm{HR}, \mathrm{CI}$, and GEDVI (Figures 3(a), 3(b), 3(c), and 3(d)). The CI increased significantly at $T_{4}, T_{5}$, and $T_{6}$ compared to baseline values and at $T_{4}$ and $T_{6}$ compared to the sham-operated group as well (Figure 3(c)). Improvement in global hemodynamics was also reflected by the significant improvement in $\mathrm{BE}$ in the shock group from $T_{2}$ to $T_{6}(1.1 \pm 2.8,3.1 \pm$ $3.4 \mathrm{mmol} \mathrm{L}^{-1}, p<0.05$, resp.), while there was no change in $\mathrm{BE}$ in the sham group $\left(5.9 \pm 1.9,6.7 \pm 2.9 \mathrm{mmol} \mathrm{L}^{-1}\right)$. The $\mathrm{P}_{\mathrm{SL}} \mathrm{CO}_{2}$ did not change significantly over time in the sham-operated group. In the shock group there was also a significant improvement during this period, still these values remained elevated as compared to baseline $\left(T_{0}\right)$. Moreover, at $T_{5} \mathrm{P}_{\mathrm{SL}} \mathrm{CO}_{2}$ was significantly higher than in the shamoperated group (Figure 4(a)). Regarding the $\mathrm{P}_{\mathrm{SL}} \mathrm{CO}_{2}$ gap, it decreased significantly by $T_{3}$ as compared to $T_{2}$ in the shock group, but it remained significantly higher as compared to $T_{0}$ throughout the resuscitation period. In the sham-operated group the $\mathrm{P}_{\mathrm{SL}} \mathrm{CO}_{2}$ gap showed a slow nonsignificant increase over time. Between $T_{3}$ and $T_{6}$ there were no significant differences between the sham and shock groups (Figure 4(b)).

Concerning the microcirculatory measurements, both $\mathrm{RBCV}_{\mathrm{SL}}$ and $\mathrm{CPR}_{\mathrm{SL}}$ increased significantly in the shock group compared to $T_{2}$, but still they remained decreased compared to the baseline values. At $180 \mathrm{~min}\left(T_{6}\right)$, there was no difference in $\mathrm{RBCV}_{\mathrm{SL}}$ between shock and shamoperated groups (Figure $5(\mathrm{a})$ ), while $\mathrm{CPR}_{\mathrm{SL}}$ in the shock group remained significantly lower than in the shamoperated group (Figure 5(b)).

Samples of the pictures in each phase can be seen as electronically submitted Supplementary Material (see Figure S1 available online at http://dx.doi.org/10.1155/2015/847152).

Fluid resuscitation resulted in a significant decrease of the $\mathrm{PcvaCO}_{2}$ at $T_{3}-T_{6}$ as compared to $T_{2}$, but $\mathrm{PcvaCO}_{2}$ changes within the shock group were significant at $T_{3}$ compared to $T_{0}$ (Figure 6(a)). $\mathrm{ScvO}_{2}$ showed a statistically significant elevation after resuscitation as compared to $T_{2}$ but remained significantly lower as compared to the baseline value at $T_{0}$ and to the sham-operated group (Figure 6(b)). In case of the oxygen extraction rate significant differences were observed between the sham and shock groups at $T_{4}-T_{6}$ (Figure 6(c)).

3.3. Correlation Analysis. Statistically significant correlation was found between $\mathrm{P}_{\mathrm{SL}} \mathrm{CO}_{2}$ gap and $\mathrm{RBCV}_{\mathrm{SL}}(r=-0.648$; $p<0.0001)$ and $\mathrm{P}_{\mathrm{SL}} \mathrm{CO}_{2}$ gap and $\mathrm{CPR}_{\mathrm{SL}}(r=-0.644$; $p<0.0001$ ) (Figures 7(a) and 7(b)). The $\mathrm{P}_{\mathrm{SL}} \mathrm{CO}_{2}$ gap also correlated with $\mathrm{ScvO}_{2}$ and $\mathrm{PcvaCO}_{2}(r=-0.504$ and $p<$ $0.0001 ; r=0.623$ and $p<0.0001$, resp.) (Figures 7(c) and 7(d)). A significant but weaker correlation was found between $\mathrm{P}_{\mathrm{SL}} \mathrm{CO}_{2}$ and $\mathrm{ScvO}_{2}(r=-0.29 ; p<0.0001)$ and $\mathrm{P}_{\mathrm{SL}} \mathrm{CO}_{2}$ and $\mathrm{PcvaCO}_{2}(r=0.405 ; p<0.0001)$. 


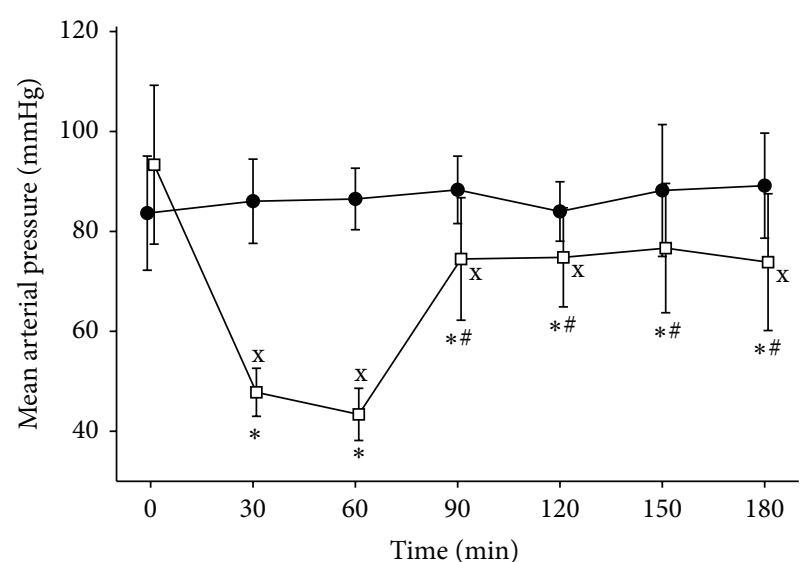

(a)

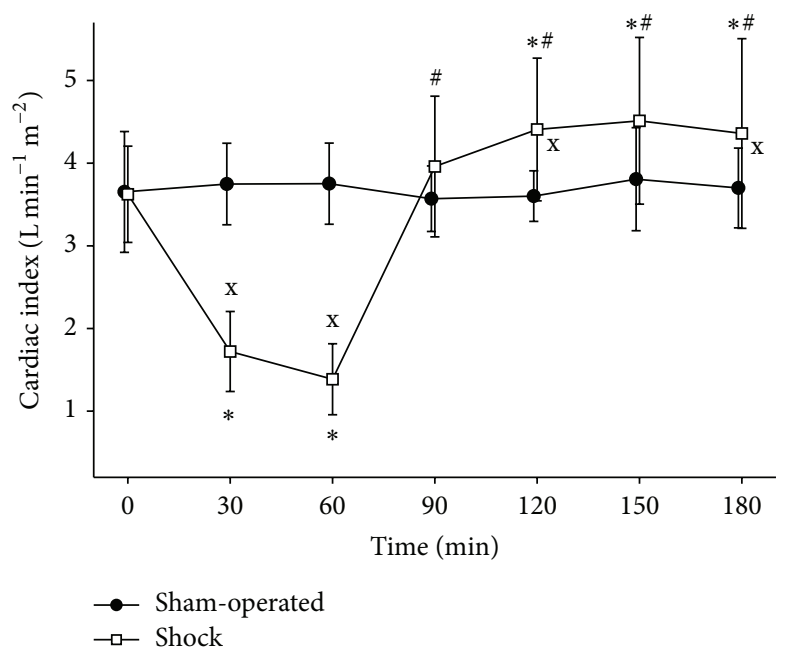

(c)

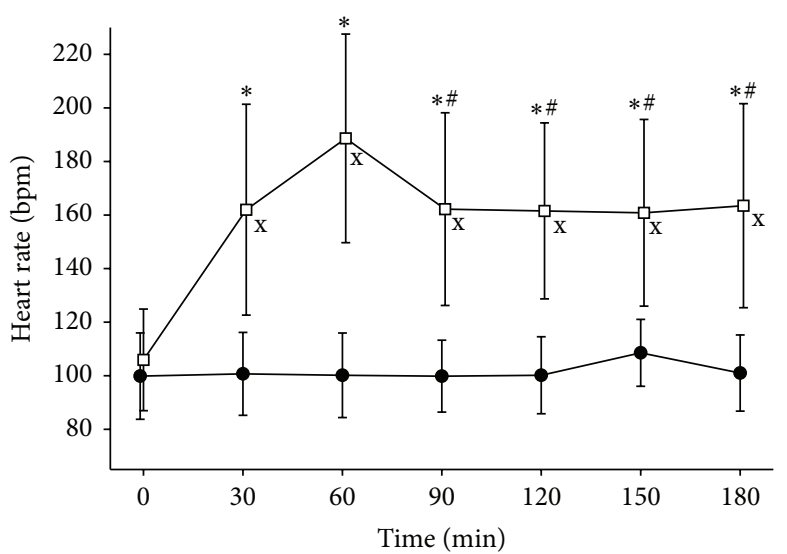

(b)

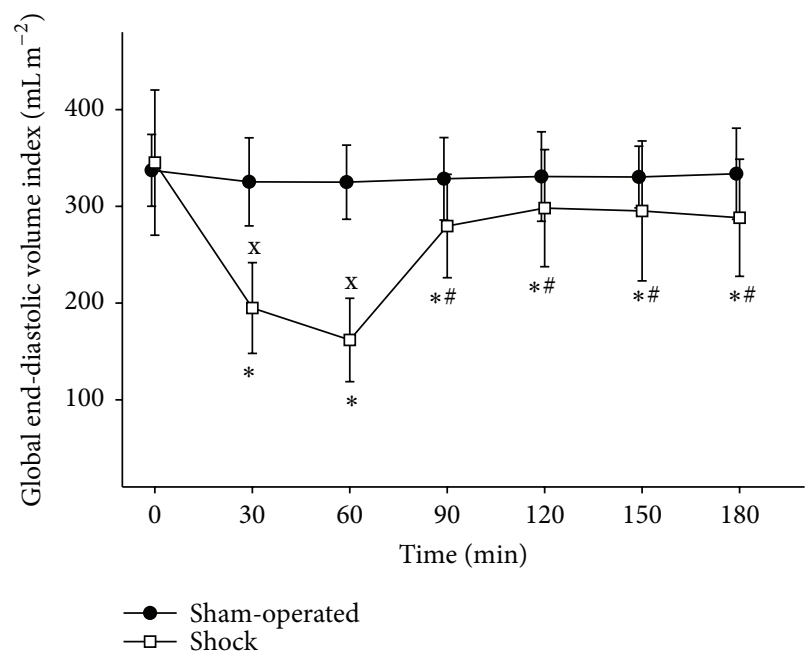

(d)

Figure 3: Macrohemodynamic parameters. Changes of macrohemodynamic parameters, mean arterial pressure (a), heart rate (b), cardiac index (c), and global end-diastolic volume index (d). ${ }^{*} p<0.05$ as compared to $0 \min \left(T_{0}\right),{ }^{*} p<0.05$ as compared to 60 min $\left(T_{2}\right)$, and ${ }^{x} p<0.05$ shock group versus sham-operated group.

\section{Discussion}

In this study we report on the first in vivo application of a new sublingual tonometric device. The major finding of this experiment is that this noninvasive monitor accurately followed the changes in submucosal postcapillary blood flow during bleeding and resuscitation. The measured values showed very good correlation with direct indices of microcirculation as determined by the well-established OPS technique and also with global measures of hypovolemia-caused oxygen debt such as $\mathrm{ScvO}_{2}$ and $\mathrm{PcvaCO}_{2}$.

4.1. Sublingual Capnometry and Microcirculation. There are different methods able to detect the increased concentrations of $\mathrm{CO}_{2}$ in the periphery. Gastric tonometry is based upon the monitoring of gastric mucosal $\mathrm{PCO}_{2}$ level; sublingual and buccal capnometry measure mucosal $\mathrm{PCO}_{2}$ of the proximal gastrointestinal tract [19-21]. Mixed venous-to-arterial or central venous-to-arterial $\mathrm{CO}_{2}$ partial pressure difference is regarded as markers describing the balance between cardiac output and oxygen consumption by peripheral tissues [22, 23].

The concept of monitoring complementary regional/local perfusion parameters in order to guide or fine-tune resuscitation strategies is rather old and well-established. Historically, one of the first methods was gastric tonometry. However, technical difficulties, long equilibration, and other confounding factors [14] hindered the widespread use of the method, leading to the withdrawal of these devices from the market. In recent years several investigators came to the conclusion that $\mathrm{PCO}_{2}$ values of the oral mucosa correlate well with gastric mucosal $\mathrm{PCO}_{2}$ parameters $[6,13,20,24]$. Although the value of sublingual capnometry in the diagnosis of circulatory failure has been reported previously [20,25], the method is not available for everyday clinical practice. The monitoring tools used for this purpose in the first experimental and clinical studies were highly sophisticated devices with special $\mathrm{PCO}_{2}$-electrodes or fiber optic sensors [26]. The device we 


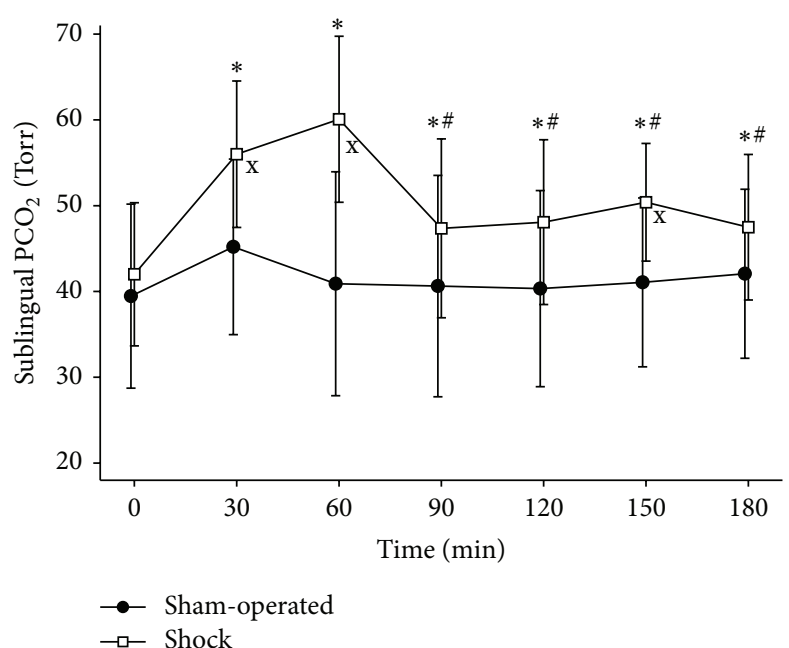

(a)

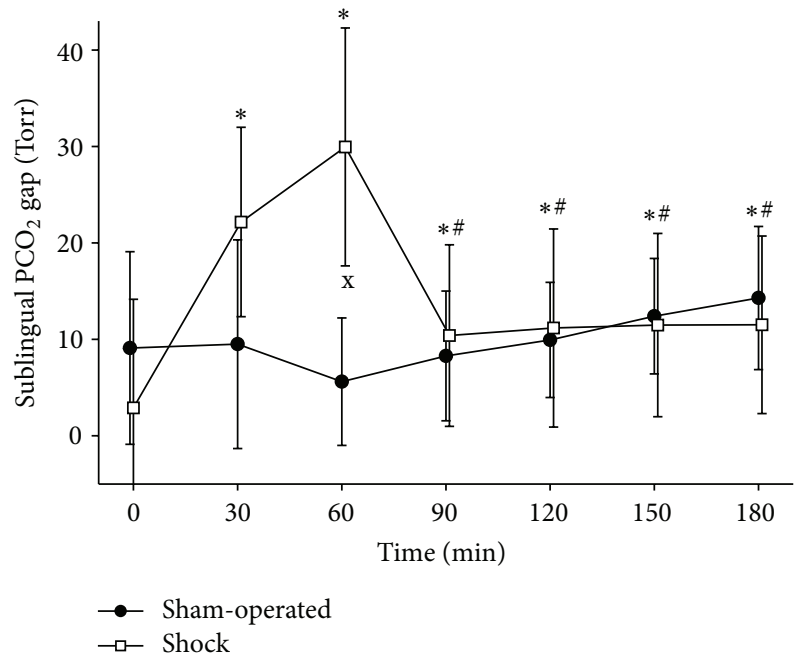

(b)

FIgURE 4: Sublingual capnometry. Changes of sublingual tonometric variables measured by the new probe, sublingual $\mathrm{PCO}_{2}(\mathrm{a})$ and sublingual $\mathrm{PCO}_{2}$ gap (b). ${ }^{*} p<0.05$ as compared to $0 \min \left(T_{0}\right),{ }^{*} p<0.05$ as compared to 60 min $\left(T_{2}\right)$, and ${ }^{\mathrm{x}} p<0.05$ shock group versus sham-operated group.

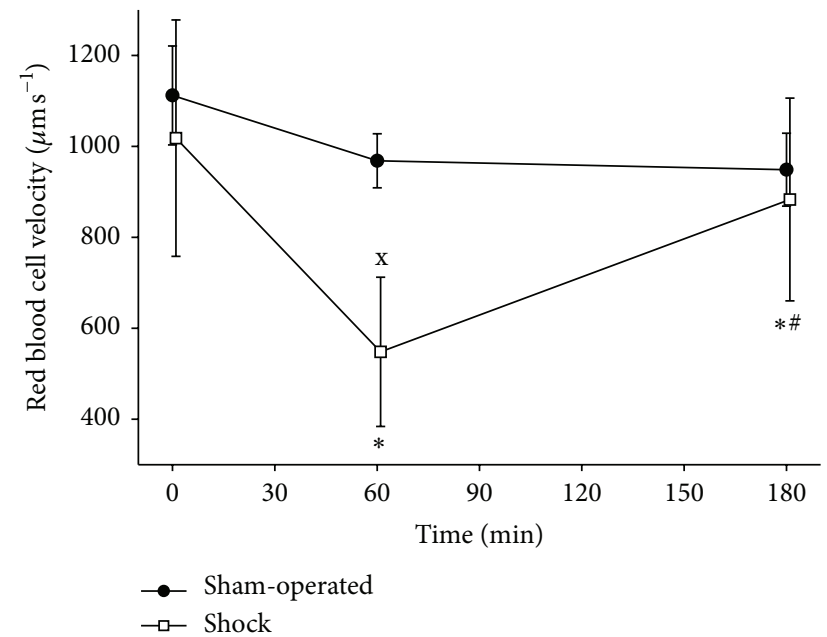

(a)

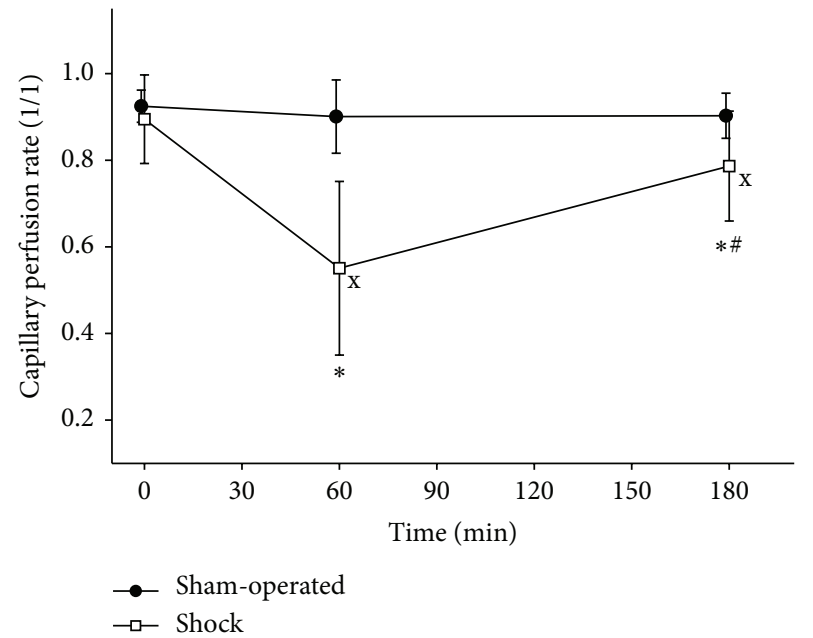

(b)

FIGURE 5: Microcirculatory parameters. Changes of microcirculatory parameters measured by orthogonal polarization spectral imaging, red blood cell velocity in postcapillary venules (a) and capillary perfusion rate (b). ${ }^{*} p<0.05$ as compared to 0 min $\left(T_{0}\right),{ }^{\#} p<0.05$ as compared to $60 \mathrm{~min}\left(T_{2}\right)$, and ${ }^{\mathrm{x}} p<0.05$ shock group versus sham-operated group.

used in the presented experimental protocol proved to be a simple, noninvasive monitor for this purpose.

According to recent studies it was suggested that even the magnitude of blood loss can be estimated by tissue capnometry, and the method may also be useful in guiding fluid resuscitation during hemorrhage. Different authors [27, 28] measured buccal $\mathrm{PCO}_{2}$ continuously during different severity of hemorrhagic shock in rats and found that tissue $\mathrm{PCO}_{2}$ monitoring was reliable in the quantitation of acute hemorrhage. Baron et al. [29] measured sublingual $\mathrm{PCO}_{2}$ in bleeding trauma patients and found similar results. In a porcine model of hemorrhagic shock $\mathrm{Xu}$ and colleagues [30] compared different volume replacement protocols based on either sublingual $\mathrm{PCO}_{2}$ or blood pressure. The animals monitored by sublingual $\mathrm{PCO}_{2}$ required smaller amount of both crystalloids and transfusion, while the microcirculation, organ functions, and survival were similar in the treatment groups. Although our experiment had different goals, the results give support to both assumptions. Loss of $50 \%$ of the circulating blood volume also increased the sublingual $\mathrm{PCO}_{2}$ by $50 \%$ : from $T_{0}=41.6 \pm 8.3$ to $T_{2}=60.1 \pm 9.6$ Torr. On the other hand, sublingual $\mathrm{PCO}_{2}$ gap increased by 5 -fold; 


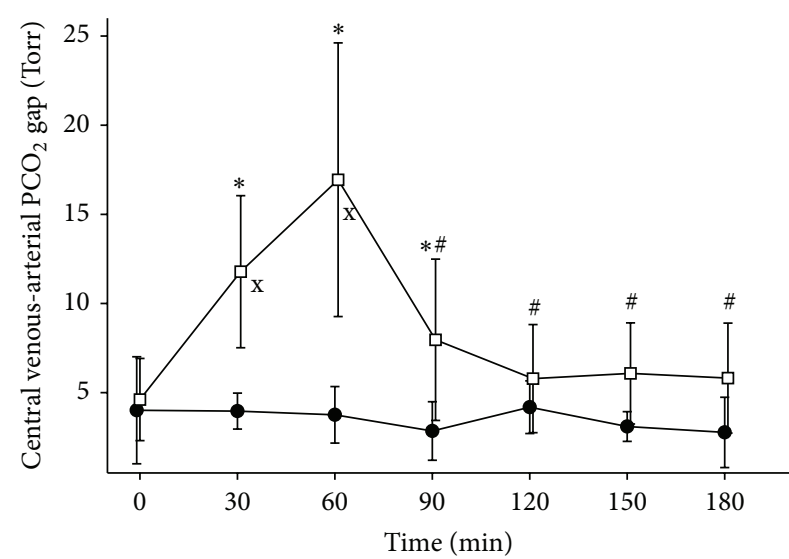

(a)

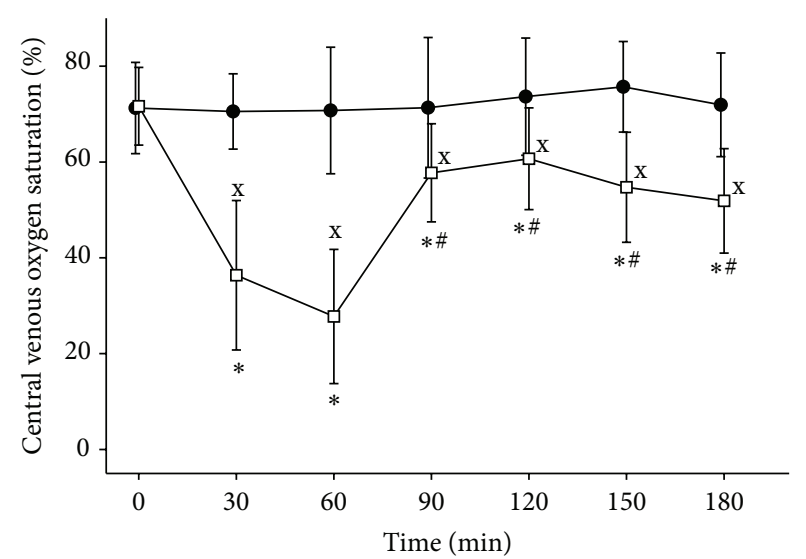

(b)

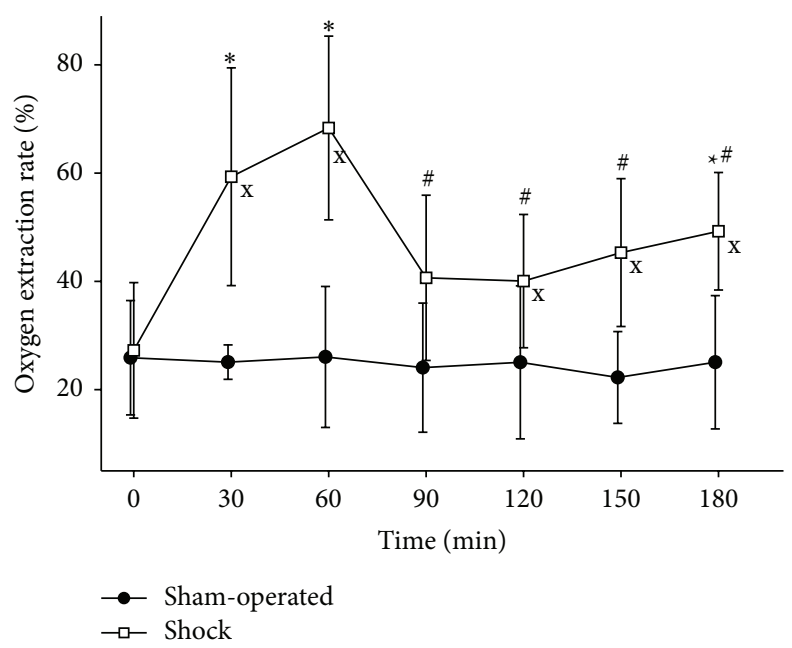

(c)

Figure 6: Central venous blood gas derived parameters. Changes of central venous blood derived parameters, central venous-arterial $\mathrm{PCO}_{2}$ gap (a), central venous oxygen saturation (b), and oxygen extraction rate (c). ${ }^{*} p<0.05$ as compared to 0 min $\left(T_{0}\right),{ }^{*} p<0.05$ as compared to $60 \min \left(T_{2}\right)$, and ${ }^{x} p<0.05$ shock group versus sham-operated group.

therefore it seems that for this purpose this parameter may be more sensitive than sublingual $\mathrm{PCO}_{2}$ on its own. We did not observe strong, significant differences in the $\mathrm{P}_{\mathrm{SL}} \mathrm{CO}_{2}$ and the $\mathrm{P}_{\mathrm{SL}} \mathrm{CO}_{2}$ gap values between the sham-operated and the shock groups in the partial resuscitation phase, but there were significant changes in the shock group reflecting the hemodynamic changes throughout the experiment. We suggest that it is the kinetics of $\mathrm{P}_{\mathrm{SL}} \mathrm{CO}_{2}$ rather than the absolute value which deserves attention. This has to be investigated in the future. In general it is important to note that $\mathrm{P}_{\mathrm{SL}} \mathrm{CO}_{2}$ or $\mathrm{P}_{\mathrm{SL}} \mathrm{CO}_{2}$ gap has different role and interpretation during "rapid" or "massive" and "slow" bleeding. No one needs additional indicators during massive bleeding with severe hypotension to confirm that the patient is in trouble, and neither is there time for these measurements. Therefore sublingual capnometry may prove its merit during slow bleeding and hypovolemia as one of the potential end points of resuscitation of the microcirculation.

Massive bleeding in our study resulted in severe perfusion abnormalities as indicated by significant deterioration of sublingual $\mathrm{CPR}$ and $\mathrm{RBCV}$, which was also reflected by changes of the sublingual $\mathrm{P}_{\mathrm{SL}} \mathrm{CO}_{2}$ gap. Although the close relationship between the sublingual perfusion and $\mathrm{PCO}_{2}$ has already been described [6,31], and investigations on mucosal $\mathrm{PCO}_{2}$ and the microcirculation of the ileum [32] have been performed in hemorrhagic shock, this is the first study to reveal a correlation between sublingual capnometry and directly measured microcirculatory parameters during hemorrhagic shock.

4.2. Sublingual Capnometry and Global Hemodynamics. Significant changes in MAP, HR, CI, and GEDVI were detected during the shock phase and during partial resuscitation, with the CI being significantly higher by the end of resuscitation as compared with the baseline, possibly because of the sustained tachycardia caused by the bleeding-related stress response. There are several studies showing that hemorrhage-caused hypovolemia is accompanied by sublingual hypoperfusion and/or the increase in $\mathrm{P}_{\mathrm{SL}} \mathrm{CO}_{2}[13,20,29]$. Nevertheless, it is 


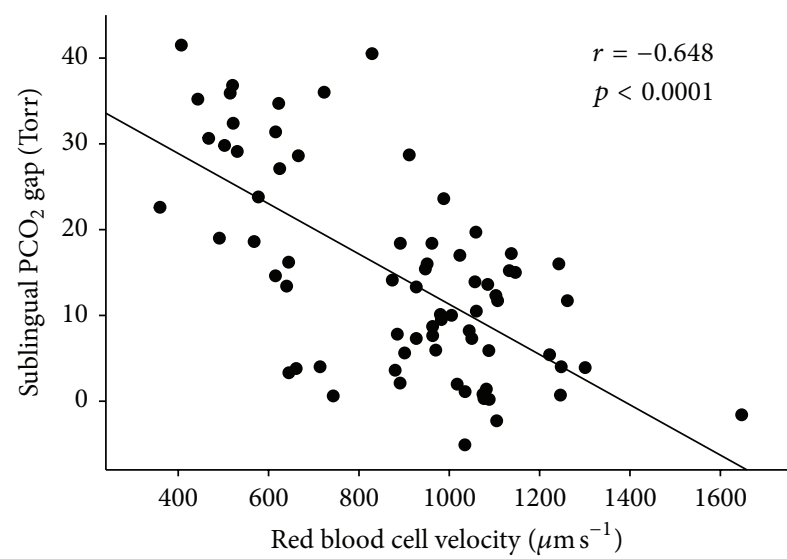

(a)

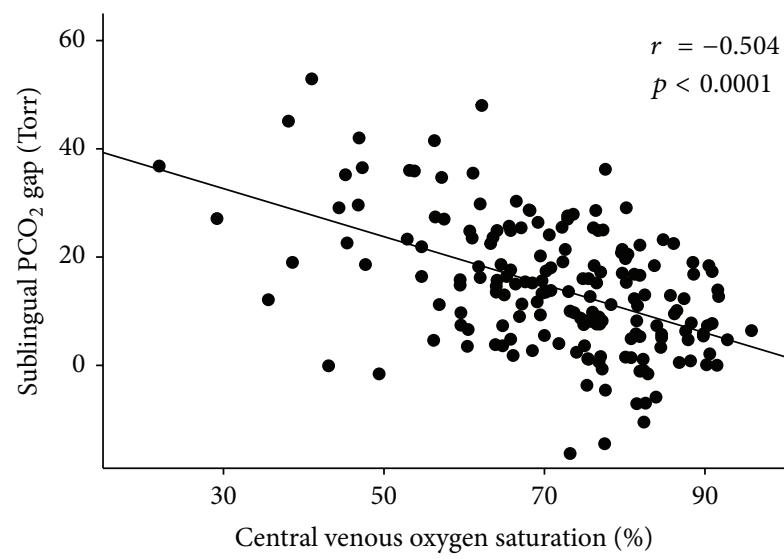

(c)

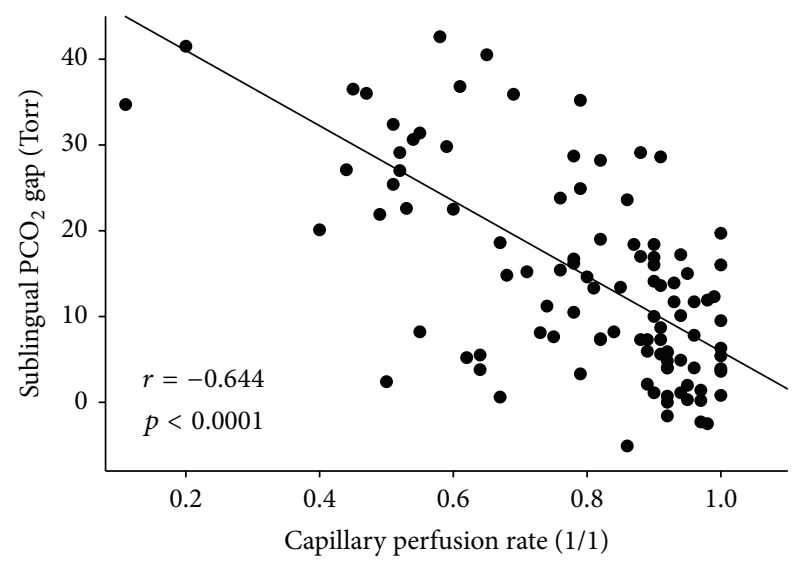

(b)

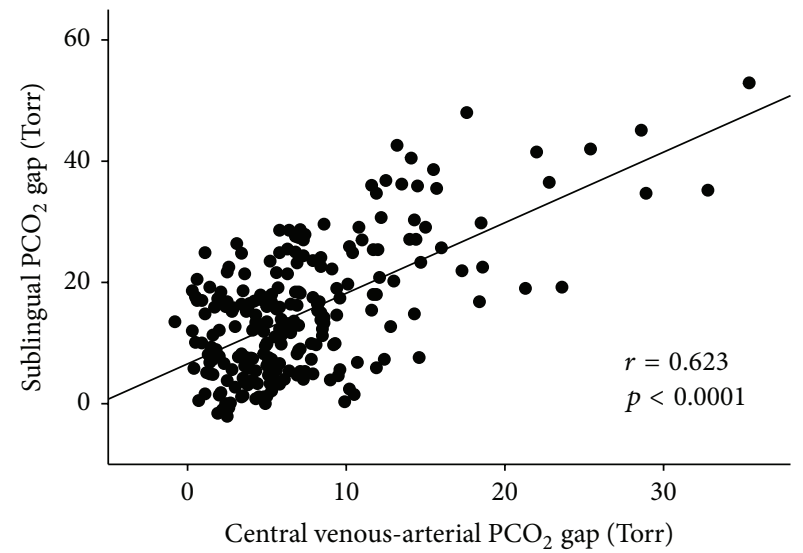

(d)

FIGURE 7: Correlations with sublingual capnometry. Relationships between sublingual mucosal-to-arterial carbon-dioxide partial pressure gap and sublingual red blood cell velocity in postcapillary venules (a), sublingual capillary perfusion rate (b), central venous oxygen saturation (c), and central venous-to-arterial carbon-dioxide partial pressure difference (d).

important to acknowledge that $\mathrm{P}_{\mathrm{SL}} \mathrm{CO}_{2}$ on its own is a poor indicator of regional circulatory changes, unless it is put in the context of the arterial and/or end-tidal $\mathrm{PCO}_{2}$. Alternatively, in order to eliminate the influence of global respiratory alterations, minute ventilation should be constant. This may explain why in a laboratory model of progressive hypovolemia caused by lower body negative pressure Chung et al. did not confirm the sensitivity of sublingual capnometry in the early phase of cardiovascular collapse [33]. In our opinion the main limitation of that study is that in their model minute ventilation was not constant (subjects were spontaneously breathing), end-tidal $\mathrm{PCO}_{2}$ decreased significantly, and they measured $\mathrm{P}_{\mathrm{SL}} \mathrm{CO}_{2}$ and not $\mathrm{P}_{\mathrm{SL}} \mathrm{CO}_{2}$ gap. By calculating gap values substantial $\mathrm{P}_{\mathrm{SL}} \mathrm{CO}_{2}-\mathrm{P}_{\mathrm{ET}} \mathrm{CO}_{2}$ gap differences could have been detected. There are other important conceptual differences between their model and the earlier experimental protocols; that is, hypovolaemia was not caused by bleeding, the observation period was only $20 \mathrm{~min}$, and the study population was young, healthy, nonsmoking subjects with presumably good physiologic reserves. Finally, the sublingual microcirculation was not monitored in this study, so the changes of sublingual microvascular perfusion during the experiment remain unknown.

4.3. Sublingual Capnometry and Oxygen Delivery/Consumption. Although the most accurate way to assess cardiac output, oxygen delivery, and consumption is invasive hemodynamic monitoring, it is often unavailable in emergencies. Simple blood gas driven variables such as $\mathrm{ScvO}_{2}$ and $\mathrm{PcvaCO}_{2}$ can help the clinician in defining the need for fluid resuscitation and red blood cell transfusion or may serve as therapeutic targets of goal-directed therapy in highrisk surgical or septic patients [34-36]. In our study $\mathrm{ScvO}_{2}$, $\mathrm{O}_{2} \mathrm{ER}$, and $\mathrm{PcvaCO}_{2}$ showed significant changes during hemorrhagic shock and partial resuscitation. Although in cases of impaired oxygen uptake $\mathrm{ScvO}_{2}$ values can be elevated $[5,37]$, our hemorrhagic shock-resuscitation model gives further support to the theory that low $\mathrm{ScvO}_{2}$ and high $\mathrm{PcvaCO}_{2}$ indicate hypovolemia and they also correlated well with $\mathrm{P}_{\mathrm{SL}} \mathrm{CO}_{2}$ gap values. In fact correlation of $\mathrm{ScvO}_{2}$ and $\mathrm{PcvaCO}_{2}$ with $\mathrm{P}_{\mathrm{SL}} \mathrm{CO}_{2}$ gap was better than with $\mathrm{P}_{\mathrm{SL}} \mathrm{CO}_{2}$, indicating that the actual condition of the microcirculation is 
reflected more precisely by gap values than by absolute values of sublingual $\mathrm{PCO}_{2}$.

\section{Conclusions}

This new capillary tonometer may be an appropriate tool for the indirect evaluation of the sublingual microcirculation. There are also some limitations to the use of this method, such as the relatively long equilibration time and the need to draw arterial blood samples to determine the $\mathrm{P}_{\mathrm{SL}} \mathrm{CO}_{2}$ gap. However, the calculation of gap values is probably not necessary if the alveolar ventilation is considered stable. In our opinion, this device can be best utilized during emergency situations (in the ICU or ER and during major/highrisk surgery), where arterial and central venous catheters are commonly used, and excessive invasiveness should therefore not be a concern.

With these restrictions we concluded that capnometryderived variables followed the microcirculatory changes and correlated with well-established indices of global hemodynamics in hypovolemia and hemorrhagic shock. Combination of these results with central venous oxygen saturation and central venous-to-arterial carbon-dioxide partial pressure differences may be complementary tools for monitoring and treating hypovolemia and hemorrhagic shock in the clinical setting.

\section{Conflict of Interests}

The authors declare that they have no conflict of interests.

\section{Authors' Contribution}

Péter Palágyi and József Kaszaki contributed equally to this work.

\section{Acknowledgments}

The authors are very grateful to Professor Domokos Boda for his outstanding technical support and guidance by the planning and the implementation of sublingual tonometric measurements. This publication is supported by the European Union and cofunded by the European Social Fund. The project title is Telemedicine-Focused Research Activities on the Field of Mathematics, Informatics and Medical Sciences. The study was also supported by research Grant OTKA K104656.

\section{References}

[1] G. Lebuffe, C. Decoene, A. Pol, A. Prat, and B. Vallet, "Regional capnometry with air-automated tonometry detects circulatory failure earlier than conventional hemodynamics after cardiac surgery," Anesthesia \& Analgesia, vol. 89, no. 5, pp. 1084-1090, 1999.

[2] C. L. Verdant, D. de Backer, A. Bruhn et al., "Evaluation of sublingual and gut mucosal microcirculation in sepsis: a quantitative analysis," Critical Care Medicine, vol. 37, no. 11, pp. 2875-2881, 2009.
[3] Y. Sakr, M.-J. Dubois, D. de Backer, J. Creteur, and J.-L. Vincent, "Persistent-microcirculatory alterations are associated with organ failure and death in patients with septic shock," Critical Care Medicine, vol. 32, no. 9, pp. 1825-1831, 2004.

[4] P. E. Marik, "Regional carbon dioxide monitoring to assess the adequacy of tissue perfusion," Current Opinion in Critical Care, vol. 11, no. 3, pp. 245-251, 2005.

[5] D. de Backer, G. Ospina-Tascon, D. Sagado, R. Favory, J. Creteur, and J.-L. Vincent, "Monitoring the microcirculation in the critically ill patient: current methods and future approaches," Intensive Care Medicine, vol. 36, no. 11, pp. 1813-1825, 2010.

[6] J. Creteur, D. de Backer, Y. Sakr, M. Koch, and J.-L. Vincent, "Sublingual capnometry tracks microcirculatory changes in septic patients," Intensive Care Medicine, vol. 32, no. 4, pp. 516523, 2006.

[7] A. Dubin, G. Murias, B. Maskin et al., "Increased blood flow prevents intramucosal acidosis in sheep endotoxemia: a controlled study," Critical Care, vol. 9, no. 2, pp. R66-R73, 2005.

[8] A. Pernat, M. H. Weil, W. Tang et al., "Effects of hyper- and hypoventilation on gastric and sublingual $\mathrm{PCO}_{2}$," Journal of Applied Physiology, vol. 87, no. 3, pp. 933-937, 1999.

[9] C. Hamilton-Davies, M. G. Mythen, J. B. Salmon, D. Jacobson, A. Shukla, and A. R. Webb, "Comparison of commonly used clinical indicators of hypovolaemia with gastrointestinal tonometry," Intensive Care Medicine, vol. 23, no. 3, pp. 276-281, 1997.

[10] N. Maynard, D. Bihari, R. Beale et al., "Assessment of splanchnic oxygenation by gastric tonometry in patients with acute circulatory failure," Journal of the American Medical Association, vol. 270, no. 10, pp. 1203-1210, 1993.

[11] P. E. Marik and A. Bankov, "Sublingual capnometry versus traditional markers of tissue oxygenation in critically ill patients," Critical Care Medicine, vol. 31, no. 3, pp. 818-822, 2003.

[12] J. Creteur, "Gastric and sublingual capnometry," Current Opinion in Critical Care, vol. 12, no. 3, pp. 272-277, 2006.

[13] H. P. Povoas, M. H. Weil, W. Tang, B. Moran, T. Kamohara, and J. Bisera, "Comparisons between sublingual and gastric tonometry during hemorrhagic shock," Chest, vol. 118, no. 4, pp. 1127-1132, 2000.

[14] J. J. Kolkman, J. A. Otte, and A. B. J. Groeneveld, "Gastrointestinal luminal $\mathrm{P}_{\mathrm{CO}_{2}}$ tonometry: an update on physiology, methodology and clinical applications," British Journal of Anaesthesia, vol. 84, no. 1, pp. 74-86, 2000.

[15] D. Boda, J. Kaszaki, and G. Tálosi, "A new simple tool for tonometric determination of the $\mathrm{PCO} 2$ in the gastrointestinal tract: in vitro and in vivo validation studies," European Journal of Anaesthesiology, vol. 23, no. 8, pp. 680-685, 2006.

[16] P. Palágyi, L. Vimláti, K. Boda, G. Tálosi, and D. Boda, "Practical experiences and in vitro and in vivo validation studies with a new gastric tonometric probe in human adult patients," Journal of Critical Care, vol. 25, no. 3, pp. 541.e9-541.e15, 2010.

[17] Z. Rózsavölgyi, D. Boda, A. Hajnal, K. Boda, and A. Somfay, "A newly developed sublingual tonometric method for the evaluation of tissue perfusion and its validation in vitro and in healthy persons in vivo and the results of the measurements in COPD patients," Critical Care Research and Practice, vol. 2014, Article ID 534130, 6 pages, 2014.

[18] A. Szabó, B. Suki, E. Csonka et al., "Flow motion in the intestinal villi during hemorrhagic shock: a new method to characterize the microcirculatory changes," Shock, vol. 21, no. 4, pp. 320-328, 2004. 
[19] S. O. Heard, "Gastric tonometry: the hemodynamic monitor of choice," Chest, vol. 123, no. 5, supplement, pp. 469S-474S, 2003.

[20] Y. Nakagawa, M. H. Weil, W. Tang et al., "Sublingual capnometry for diagnosis and quantitation of circulatory shock," American Journal of Respiratory and Critical Care Medicine, vol. 157, no. 6 I, pp. 1838-1843, 1998.

[21] T. Pellis, M. H. Weil, W. Tang, S. Sun, P. Csapozi, and C. Castillo, "Increases in both buccal and sublingual partial pressure of carbon dioxide reflect decreases of tissue blood flows in a porcine model during hemorrhagic shock," Journal of TraumaInjury Infection \& Critical Care, vol. 58, no. 4, pp. 817-824, 2005.

[22] J. Cuschieri, E. P. Rivers, M. W. Donnino et al., "Central venousarterial carbon dioxide difference as an indicator of cardiac index," Intensive Care Medicine, vol. 31, no. 6, pp. 818-822, 2005.

[23] B. Lamia, X. Monnet, and J. L. Teboul, "Meaning of arteriovenous PCO2 difference in circulatory shock," Minerva Anestesiologica, vol. 72, no. 6, pp. 597-604, 2006.

[24] P. E. Marik, "Sublingual capnography: a clinical validation study," Chest, vol. 120, no. 3, pp. 923-927, 2001.

[25] M. H. Weil, Y. Nakagawa, W. Tang et al., "Sublingual capnometry: a new noninvasive measurement for diagnosis and quantitation of severity of circulatory shock," Critical Care Medicine, vol. 27, no. 7, pp. 1225-1229, 1999.

[26] A. T. Maciel, J. Creteur, and J.-L. Vincent, "Tissue capnometry: does the answer lie under the tongue?" Intensive Care Medicine, vol. 30, no. 12, pp. 2157-2165, 2004.

[27] G. A. A. M. Cammarata, M. H. Weil, C. J. Castillo et al., "Buccal capnometry for quantitating the severity of hemorrhagic shock," Shock, vol. 31, no. 2, pp. 207-211, 2009.

[28] H. Lu, J. Zheng, P. Zhao, G. Zhang, and T. Wu, "Buccal partial pressure of carbon dioxide outweighs traditional vital signs in predicting the severity of hemorrhagic shock in a rat model," Journal of Surgical Research, vol. 187, no. 1, pp. 262-269, 2014.

[29] B. J. Baron, R. Sinert, S. Zehtabchi, K. L. Stavile, and T. M. Scalea, "Diagnostic utility of sublingual PCO2 for detecting hemorrhage in penetrating trauma patients," Journal of Trauma, vol. 57, no. 1, pp. 69-74, 2004.

[30] J. Xu, L. Ma, S. Sun et al., "Fluid resuscitation guided by sublingual partial pressure of carbon dioxide during hemorrhagic shock in a porcine model," Shock, vol. 39, no. 4, pp. 361-365, 2013.

[31] X. Jin, M. H. Weil, S. Sun, W. Tang, J. Bisera, and E. J. Mason, "Decreases in organ blood flows associated with increases in sublingual $\mathrm{PCO}_{2}$ during hemorrhagic shock," Journal of Applied Physiology, vol. 85, no. 6, pp. 2360-2364, 1998.

[32] A. Dubin, M. O. Pozo, G. Ferrara et al., "Systemic and microcirculatory responses to progressive hemorrhage," Intensive Care Medicine, vol. 35, no. 3, pp. 556-564, 2009.

[33] K. K. Chung, K. L. Ryan, C. A. Rickards et al., "Progressive reduction in central blood volume is not detected by sublingual capnography," Shock, vol. 37, no. 6, pp. 586-591, 2012.

[34] S. Kocsi, G. Demeter, J. Fogas, D. Érces, J. Kaszaki, and Z. Molnár, "Central venous oxygen saturation is a good indicator of altered oxygen balance in isovolemic anemia," Acta Anaesthesiologica Scandinavica, vol. 56, no. 3, pp. 291-297, 2012.

[35] E. Futier, E. Robin, M. Jabaudon et al., "Central venous $\mathrm{O}_{2}$ saturation and venous-to-arterial $\mathrm{CO}_{2}$ difference as complementary tools for goal-directed therapy during high-risk surgery," Critical Care, vol. 14, no. 5, article R193, 2010.

[36] P. A. van Beest, M. C. Lont, N. D. Holman, B. Loef, M. A. Kuiper, and E. C. Boerma, "Central venous-arterial $\mathrm{P}_{\mathrm{CO}_{2}}$ difference as a tool in resuscitation of septic patients," Intensive Care Medicine, vol. 39, no. 6, pp. 1034-1039, 2013.

[37] P. Krafft, H. Steltzer, M. Hiesmayr, W. Klimscha, and A. F. Hammerle, "Mixed venous oxygen saturation in critically III septic shock patients: the role of defined events," Chest, vol. 103, no. 3, pp. 900-906, 1993. 


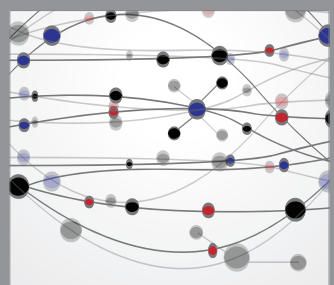

The Scientific World Journal
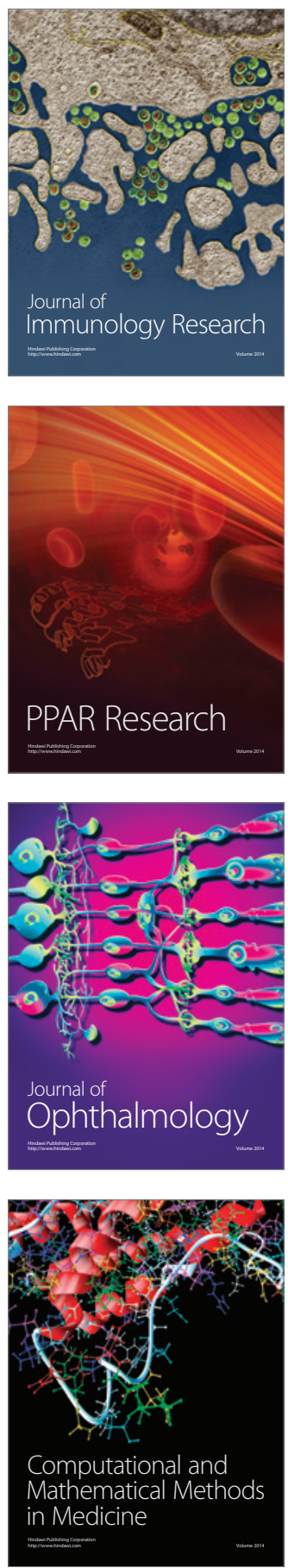

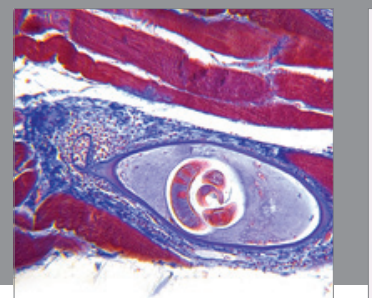

Gastroenterology

Research and Practice
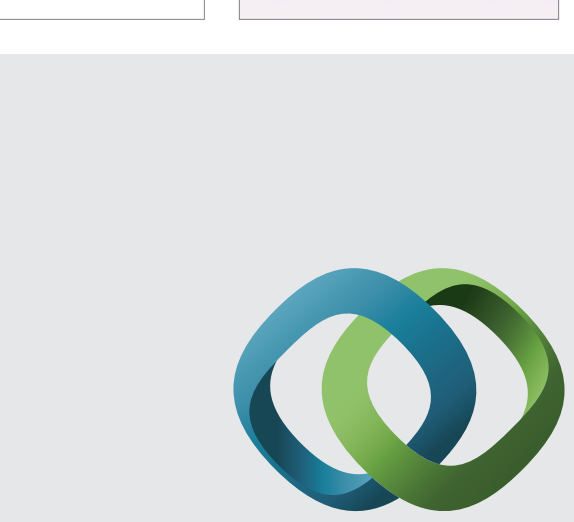

\section{Hindawi}

Submit your manuscripts at

http://www.hindawi.com
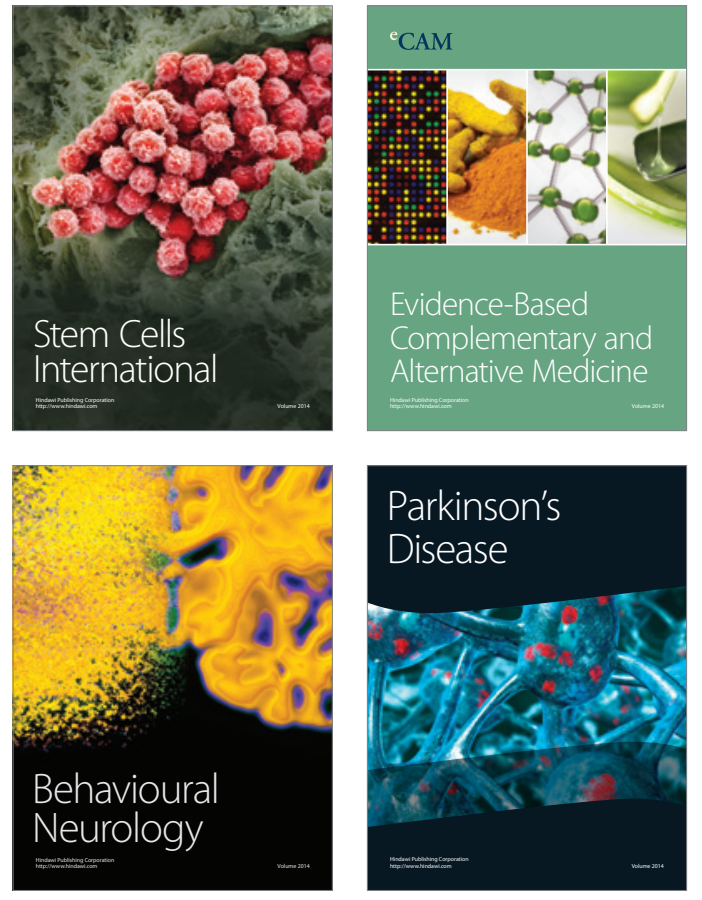
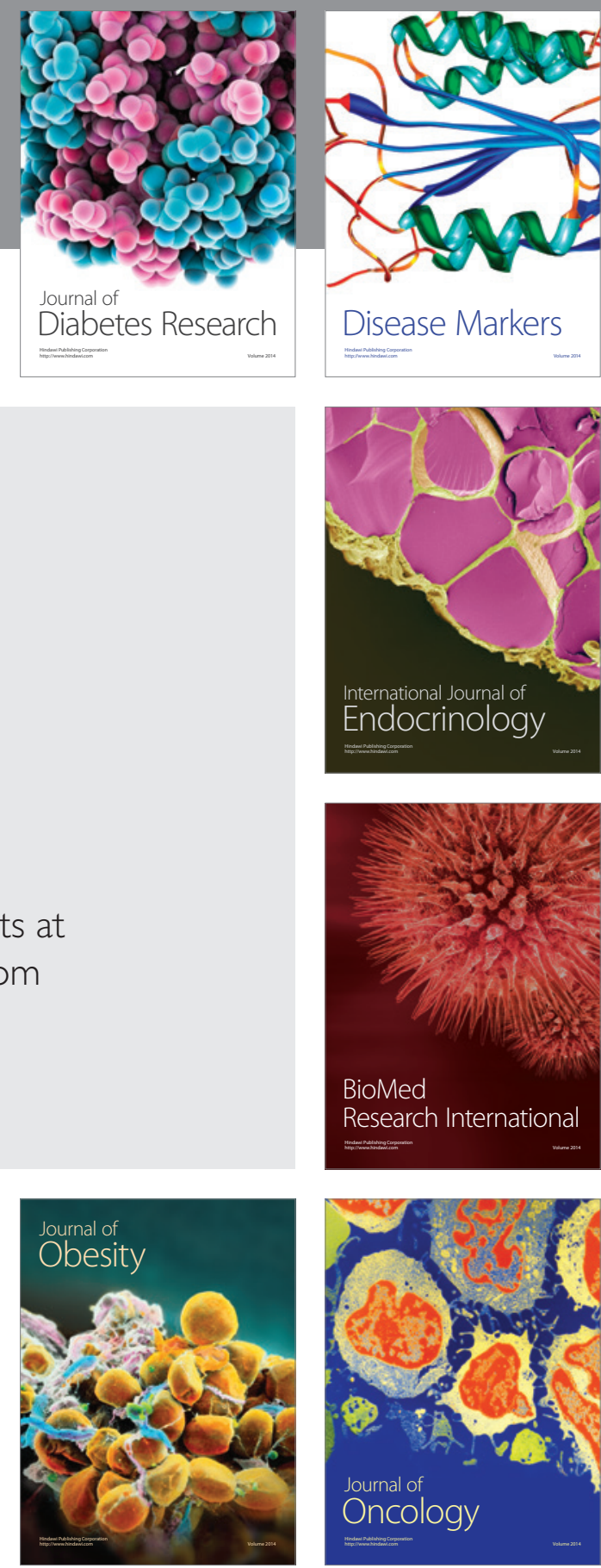

Disease Markers
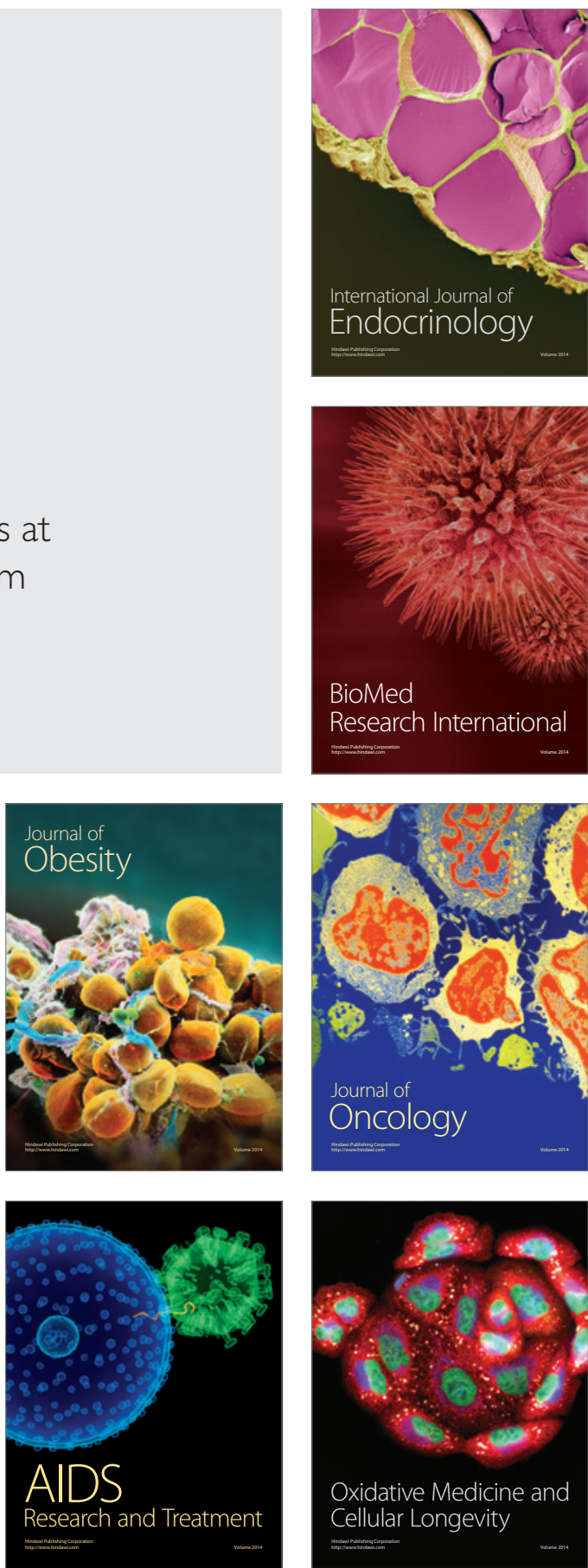